\title{
ANÁLISE: HISTÓRIA DE VIDA E NARRATIVAS INTERATIVAS EM CONTEXTO DA PANDEMIA DO CORONAVÍRUS
}

\section{ARTIGO ORIGINAL}

MALDONADO, Gabriel Orlando Quiñones ${ }^{1}$

MALDONADO, Gabriel Orlando Quiñones. Análise: História de vida e narrativas interativas em contexto da pandemia do Coronavírus. Revista Científica Multidisciplinar Núcleo do Conhecimento. Ano 05, Ed. 08, Vol. 02, pp. 28-35. Agosto de 2020. ISSN: 2448-0959, Link de acesso: https://www.nucleodoconhecimento.com.br/letras/historia-de-vida

\section{RESUMO}

O presente artigo fundamenta-se na área da Sociolinguística Interacional e propõe a análise de trechos concernentes à uma história de vida e às narrativas interativas em contextos da pandemia do Coronavírus. Coletou-se como referência um primeiro corpus escrito e um segundo corpus oral baseados em narrativas de vida. Nesta análise de histórias de vida e de narrativas interativas em contexto da doença do Coronavírus temos uma sequência discursiva que nos permitiu avaliar e interpretar

${ }^{1}$ Pós-doutor em Educação com investigação em Sociolinguística Musical Brasileira pela Universidade Virtual de Estudos Superiores - UNIVES no México (2020); Doutor em Ensino da Língua Portuguesa pela Bircham Internacional University em Madrid Espanha (2018); Mestre em Línguas, Culturas e Sociedades em Ambientes Multilíngues - Francês Língua Estrangeira pela "Université des Antilles” em Martinica (M1-2016 / M2-2018); Pós-graduado (Especialização) em Estudos de Língua Portuguesa: Investigação e Ensino pela Universidade Aberta de Portugal (2014): Graduado em Línguas Modernas, habilitação em Português e Francês, pela Universidad de Puerto Rico - Recinto de Río Pedras (2009). 
um conto e várias experiências vividas nesse tempo de pandemia que o nosso planeta tem encarado até o momento da coleta de dados.

Palavras-chave: Sociolinguística Interacional, história de vida, narrativa interativa.

\section{INTRODUÇÃO}

A chegada inesperada do Coronavírus causou mudanças significativas na humanidade. A vida cotidiana que conhecíamos foi modificada, alterada e até suspensa por um longo período de quarentena. Segundo Goffman (1967, p. 135): "quando ocorre um incidente e o envolvimento espontâneo é ameaçado, a realidade é ameaçada". Todos nós já vimos a necessidade de modificar o ambiente social, emocional e espiritual devido ao medo de contágio por esse vírus que, desconhecendo a sua origem e a sua erradicação, nos ataca silenciosamente. Assim: "eles serão forçados a aceitar alguns eventos como sinais convencionais ou naturais de algo que não está diretamente disponível para os sentidos" (Idem, p. 140, tradução minha). Com essa situação, novas narrativas de vida começaram a surgir. A história toma uma nova direção que marcará o nascimento de uma nova humanidade, que se desenvolverá com novos códigos civis, novas formas sociais e com mais consciência ambiental.

\section{A SOCIOLINGUÍSTICA INTERACIONAL}

As investigações baseadas na Sociolinguística Interacional são uma ótima forma de se contribuir para com a compreensão das mais diferentes interações sociais que ocorrem diariamente nas nossas vidas, em momentos distintos. Os recursos disponíveis contribuem para a compreensão das histórias de vida, das narrativas interativas e é possível conhecer melhor o ponto de partida das diferentes interações. $\mathrm{Na}$ esfera profissional, professores, linguistas ou interessados nesta área, com esses recursos fornecidos pela Sociolinguística Interacional, podem entender melhor às pessoas ao seu redor. Além disso, pode-se conseguir chegar as boas práticas das interações conversacionais. 
Segundo Gumperz (1982, pp. 24-25), "o sociolinguista que trabalha nessa tradição começa registrando o discurso cotidiano de falantes selecionados de acordo com critérios de amostragem sociológica como representativos de um grupo ou comunidade em particular e não de acordo com critérios de história da família". Continua afirmando que também não está de acordo com a "[...] formação linguística, como nos estudos dialetológicos anteriores. Além disso, os procedimentos de obtenção partem dos métodos convencionais de questionário de dialeto, nos quais os falantes são questionados diretamente e solicitados a ilustrar ou produzir amostras de fala" (Idem).

\section{ANÁLISE DE HISTÓRIAS DE VIDA}

As histórias de vida representam uma propriedade de pesquisa da Sociolinguística Interacional que fornece uma explicação acerca de eventos e costumes para conhecer como é uma pessoa e como se desenvolve na sociedade. Isso apresenta as atuações de um indivíduo como representante e colaborador da vida social a partir da narração dos eventos vivenciados e da transmissão da sua experiência de vida. Isso inclui os depoimentos acumulados sobre a vida do sujeito: escolaridade, saúde, família, entre outros, realizados pelo pesquisador, que atua como narrador, moderador e relator. Com as narrativas de vida coletadas por meio de entrevistas, é obtido o testemunho individual de uma pessoa referente aos eventos que a colocaram em contato com o que nos quer transmitir a partir da sua narração.

Um fato vivido é narrado com a sua causa e desenvolvimento, com progressões ou regressões. Nesse contexto, pode-se auferir que as narrativas investigadas são ricas em termos de história, uma vez que admite-se, atualmente, os campos da psicolinguística e da psicologia cognitiva e do desenvolvimento: "[...] no entanto, poucos deles conseguem capturar a natureza bidirecional das narrativas e o papel interativo das pressões locais e globais na produção e compreensão da narrativa" (BAMBERG; MARCHMAN, 1990, p. 61). 


\subsection{ANÁLISE: "MEU HERÓI ÉS TU”. COMO AS CRIANÇAS PODEM COMBATER A COVID-19!}

O objetivo fundamental desta análise é aprofundar um pouco mais o conhecimento sobre a estrutura e o desenvolvimento das estórias de vida. Nesse caso, defino estórias como um conto em que a narração penetrará nas condições de vida atuais, reunindo dados importantes desde o início, na trama e no final da narração, a fim de capturar a atenção do leitor, neste caso, as crianças. O desenvolvimento desta história "Meu Herói és Tu" toma forma a partir de um vocabulário simples sobre como adaptarse ao novo estilo de vida causado pela pandemia do Coronavírus. Segundo Bamberg e Marchman (1990, p. 112), "cada evento é visto no contexto da narrativa, a fim de obter uma compreensão da relação entre a estrutura da história e sua manifestação linguística".

Figura 1: Meu herói és tu

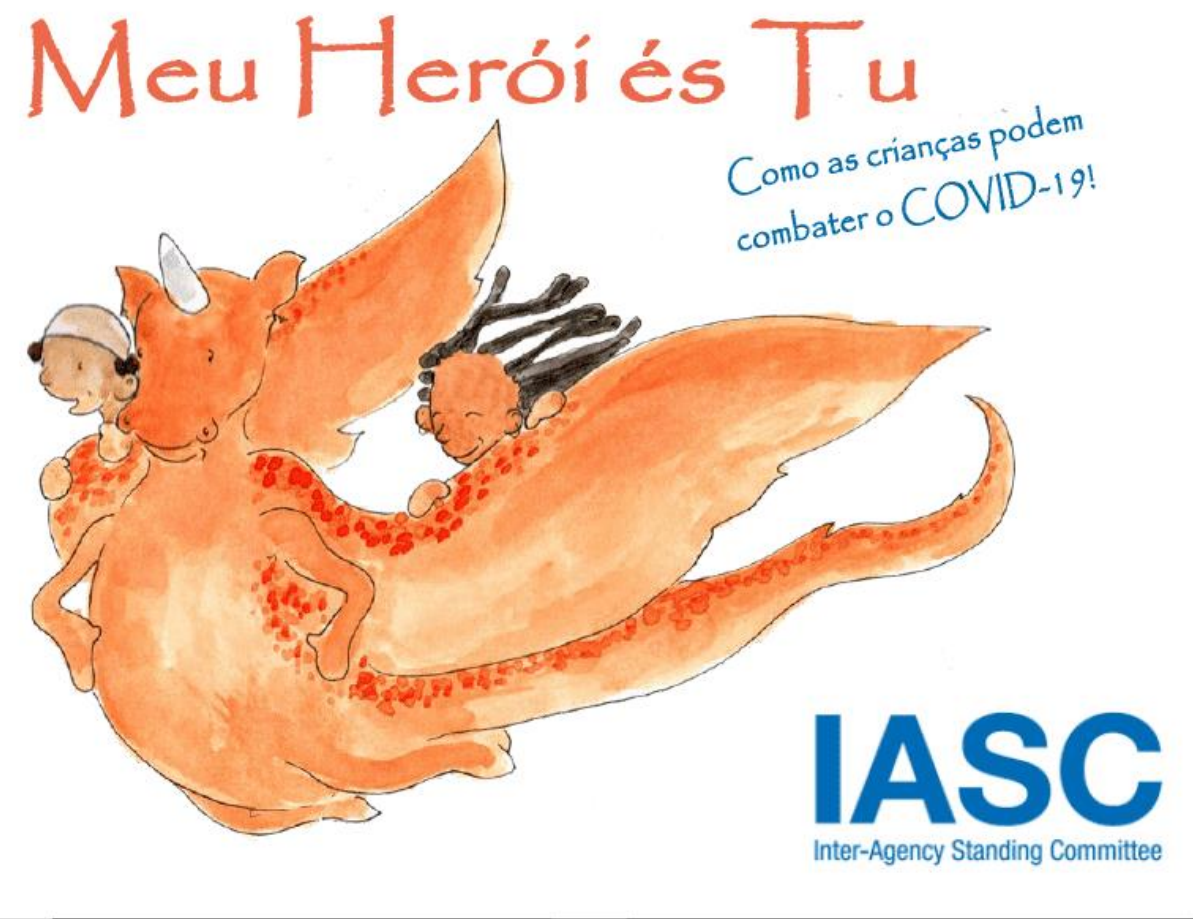

Fonte: IASC (2020) 


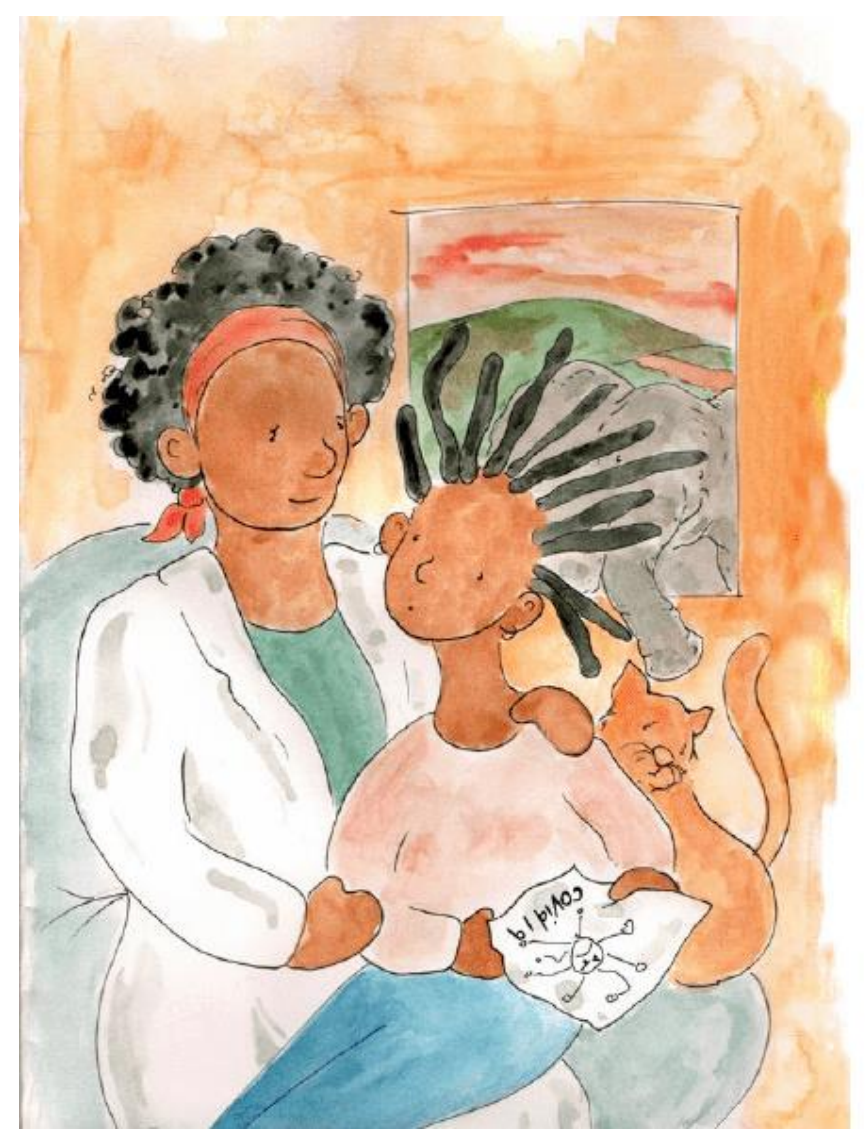

\author{
A mãe de Sara é a sua heroína porque ela é a \\ melhor mãe e melhor cientista do mundo. Mas \\ até a mãe de Sara não consegue encontrar uma \\ cura para o coronavírus. \\ "Como é o COVID-19?", Sara perguntou à sua \\ mãe. \\ "O COVID-19, ou o coronavírus, é tão pequeno \\ que não conseguimos ver", disse a mãe. "Mas ele \\ espalha-se em tosses e espirros de pessoas \\ doentes, e quando elas tocam pessoas ou coisas \\ ao seu redor. As pessoas doentes têm febre e \\ tosse e podem ter problemas para respirar." \\ "Então, não podemos combater o coronavírus \\ porque não consegtuimos vê-lo?", Sara \\ perguntou. \\ "Nós podemos combatê-1o", đisse a mãe de Sara. \\ "É por isso que eu preciso que estejas segura, \\ Sara. O virus afeta muitos tipos de pessoas e toda \\ a gente pode ajudar-nos a combatê-1o. As \\ crianças são especiais e podem ajudar também. \\ Tu precisas de ficar segura por todos nós. Eu \\ preciso que tu sejas a minha heroina."
}

Fonte: IASC (2020)

É uma narrativa curta, que apresenta eventos reais, cuja origem é a história de vida da humanidade nessa pandemia. O objetivo é orientar as crianças acerca do controle da sua segurança, da família e dos amigos. A partir do "Meu Herói és Tu", muitos aspetos importantes podem ser trabalhados para o desenvolvimento linguístico das crianças. Segundo Bamberg e Marchman (1990, p. 60), "narrando uma história simples, as crianças enfrentam a tarefa de escolher a sua perspectiva. Ao mesmo tempo, eles devem comunicar a perspectiva dentro dos limites dos meios linguísticos disponíveis para eles." Nesta estória de vida, vê-se um conto adaptado com imagens e texto escrito, em que a situação atual da COVID-19 é narrada com vistas a enfatizar que todas as personagens são heróis representativos do nosso ambiente real.

Segundo Bamberg e Marchman (1990, p. 63), "vários contrastes linguísticos em uma narrativa simples de livro de figuras foram investigados por seu papel na definição discursiva dos limites dos episódios e por contribuir para o estabelecimento de uma estrutura coerente da história." Na estória existe um narrador que leva o leitor ou 
ouvinte ao longo de um caminho a partir da situação inicial, que se desenvolve e complica, constituindo o conflito ou o nó, até chegar ao resultado ou solução. $\mathrm{Na}$ situação inicial, prevalecem o tempo e o espaço narrativo, que servem de estrutura para a narração. Essa história é narrada no tempo presente do indicativo, pois foi produzida durante os eventos ativos do Coronavírus.

Mais adiante, esperemos que esta narração seja usada com os tempos verbais do pretérito, assim poderíamos dizer que o pior da Covid-19 findou. Segundo Lopes (1996, p. 360), "os eventos vão-se ordenando temporalmente no interior do texto, uns em função dos outros, e a localização temporal relativa vai sendo gradualmente alterada/construída pela própria dinâmica discursiva."

Trecho 1: "A mãe de Sara é a sua heroína porque ela é a melhor mãe e a melhor cientista do mundo. Mas até a mãe de Sara não consegue encontrar uma cura para o coronavírus".

A ideia principal é o ponto de partida da estória, é a essência do que o conto quer expressar, uma vez que a Covid-19 é real. Uma das ideias apresentadas é como fazer as pessoas entenderem, a partir da narração desta estória de vida atual, os problemas que são apresentados pelos personagens para que as crianças possam usar as suas capacidades linguísticas para entender e encarar a sua nova convivência social de vida. Esta estória também poderia ser usada na sala de aula de Português Língua Estrangeira. Segundo Bamberg e Marchman (1990, p. 59), "o monólogo narrativo é escolhido como base de dados para investigar mais detalhadamente o conhecimento linguístico das crianças em seu uso real". Por exemplo, não poder frequentar a escola devido aos problemas de contágio pela Covid-19.

Trecho 2: "Como é a COVID-19?", Sara perguntou à sua mãe.

Trecho 3: "A COVID-19, ou o coronavírus, é tão pequeno que não conseguimos ver", disse a mãe. "Mas ele espalha-se em tosses e espirros de pessoas doentes, e quando elas tocam pessoas ou coisas ao seu redor. As pessoas doentes têm febre e tosse e podem ter problemas para respirar".

A seguir, apresentar-se a análise das narrativas interativas de forma contextualizada. 


\section{ANÁLISE DE NARRATIVAS INTERATIVAS EM CONTEXTO}

O discurso direto nas narrativas da vida nos mostra os diferentes eventos pelos quais as pessoas passam todos os dias. Macaulay (1987), indica que o falante deve recriar essa narração por meio da expressão nas suas palavras. Segundo Macaulay (1987, p. 29), "o uso do discurso direto citado acrescenta vivacidade a uma narrativa, oferece a possibilidade de uma perspectiva diferente e pode dar uma impressão de lembrança autêntica de um evento, embora não seja sensato supor que ele necessariamente reporte as palavras reais usadas". Alude, ainda, que: "[...] ao apelar para citar as palavras reais ditas, o orador está dando ao ouvinte a oportunidade de interpretar a afirmação sem o risco de ser distorcida pela forma em que é relatada".

\subsection{ANÁLISE: PESSOAS QUE ENFRENTAM A COVID-19 CONTAM COMO É A VIDA APÓS A DOENÇA}

As narrativas de vida transmitidas pela emissora CBN concordam com o relato de várias pessoas que enfrentaram a Covid-19. As histórias de vida que essas pessoas oferecem servem como uma estrutura interpretativa a partir da qual obtemos o sentimento de experiência humana ao enfrentar a pandemia de Covid-19.

[...] na análise das narrativas de experiência de vida em emissões de rádio, os participantes realizam espontaneamente identidades locais, relevantes para a construção de uma imagem de si próprios com um determinado estatuto: participantes ratificados ou como "experts", identificados em função de parâmetros como o sexo, a profissão, a idade ou relativamente a uma história vivida, como testemunho de uma vivência que queiram ver partilhada (ALMEIDA, 2011, pp. 11-12).

Atentemos a entrevista que fez o repórter Matheus Meirelles a vários brasileiros espalhados pelo mundo.

- Emissora: Rádio CBN (Central Brasileira de Notícias) em São Paulo.

- Duração: 04.58

- Repórter: Matheus Meirelles

- Entrevistados: Vários 
Nesta entrevista, o repórter desempenha o papel de locutor moderador para controlar o tempo que talvez tenha sido disponibilizado para realizar as diferentes narrações. $O$ repórter faz uma introdução narrando que, após 6 meses decorridos da pandemia de Covid-19, essas narrativas de vida começaram a surgir com base na experiência com a doença que afeta o nosso planeta.

Narrador: $\mathrm{O}$ enfrentamento e a superação do coronavírus mudaram a vida de muitas pessoas no Brasil e no mundo. As histórias, as lembranças e, principalmente, as sequelas físicas e psicológicas passam a fazer parte do dia a dia da população. Para pacientes e médicos que enfrentaram a Covid-19, uma possível vacina ou cura para a doença não significam um ponto final (MEIRELLES, 2020, s.p).

O narrador faz a introdução para cada pessoa entrevistada, apresentando, assim, a caracterização da idade, estudos, profissão e até o país ou estado no qual estavam estabelecidos no momento preciso da sua narrativa de vida. Com a ação do narrador, percebe-se que o ponto principal é conhecer as histórias, as experiências, os sentimentos e as emoções das pessoas diante da Covid-19 e como é sua vida após a doença. Segundo Günthner (2011), a indexicalidade aprimora ou amplia a capacidade de entender como conceitos como identidade, emoções, posições afetivas e ideologia trabalham em interação.

Trecho: 3

$\rightarrow$ Narrador: "A estudante Mariana Diamantino, de 31 anos, faz doutorado em direito em Paris, na França. Distante de casa, recebeu um diagnóstico negativo para a doença, mas se assustou com os sintomas."

$\rightarrow$ Entrevistado 1: "Eu tive a sorte de ter uma versão branda, vamos dizer. Se eu for tirar uma lição positiva disso, é que possibilitou ter uma real dimensão do impacto na saúde física individual, ter muita empatia pelas pessoas que passaram por tratamento hospitalar e pelos falecimentos que ocorreram."

Trecho 4:

$\rightarrow$ Narrador: "No Brasil, em São Paulo, Rosana Melo, de 54 anos, também passou a refletir depois do diagnóstico. Para ela, a doença prova que há situações que não se pode controlar." 
$\rightarrow$ Entrevistado 2: "Os médicos não dão uma certeza para a gente. Eles também estão ali na luta. O que vai mudar é que as pessoas que passaram por isso, cada um tem uma experiência pessoal. Isso também mostra que a gente não tem o poder de nada, não pode controlar nada".

Trecho 5:

$\rightarrow$ Narrador: "No Rio de Janeiro, o técnico em enfermagem da UTI do Hospital Samaritano, Júnior César de Oliveira, estava na linha de frente do combate à Covid-19. Ele chegou a ter suspeita de morte cerebral, mas se recuperou e está em fase de reabilitação. Agora, dá mais valor às pequenas coisas."

$\rightarrow$ Entrevistado 3: "Depois da Covid, você começa a dar muito mais valor às pessoas, às pequenas coisas. $O$ respirar, o beber água. Olhar para o outro com mais carinho, ter mais simpatia com o próximo. Eu fico muito assustado, sabe, de ver as pessoas não usando máscara. É uma doença muito cruel. Eu perdi 20 quilos em 35 dias. É uma doença que tira de você o bem mais importante, que é o respirar. Você está se afogando acordado" (MEIRELLES, 2020, s.p).

Nesses trechos, vêm-se frases sublinhadas nas quais os entrevistados narram no tempo verbal do pretérito as suas histórias de vida. As frases foram sublinhadas para a análise dessas narrações. As narrativas interativas dessas pessoas baseiam-se no contexto da doença de Covid-19. Os tempos verbais da narrativa variam com a evolução das intervenções em que vemos uma boa coesão e coerência. Segundo Lopes (1996, p. 353), "a relação de anterioridade relativamente ao agora da enunciação é expressa basicamente pelo Pretérito Perfeito Simples e pelo Imperfeito; a relação de simultaneidade é dada pelo Presente e a relação de posterioridade encontra expressão linguística no Futuro." Também temos outros tempos verbais como:

O futuro do subjuntivo: $\rightarrow$ Trecho 3 entrevistado 1: "se eu for tirar uma lição".

O presente do indicativo: $\rightarrow$ Trecho 4 entrevistado 2: "Os médicos não dão uma certeza para a gente".

O futuro próximo: $\rightarrow$ Trecho 4 entrevistado 2: "O que vai mudar é..." 
Adjunto adverbial temporal 'depois': Neste trecho vemos uma progressão temporal na narração: $\rightarrow$ Trecho 5 entrevistado 3: "Depois da Covid..."

Com esta análise, evidencia-se a importância de se recorrer à essas narrativas para entendermos todos os reflexos futuros da Covid-19.

\section{CONSIDERAÇÕES FINAIS}

Nesta análise de histórias de vida e de narrativas interativas em contexto da doença do Coronavírus, temos uma sequência discursiva que nos permitiu avaliar e interpretar um conto e várias experiencias vividas nesse tempo de pandemia. Segundo Bastos e Biar, (2015), pode-se dizer que as análises são de natureza qualitativa e interpretativa, interessadas, como se disse, no que acontece na vida social. Concluindo, a primeira análise da história "Meu Herói és Tu" mostra-se a narrativa da vida atual da nossa humanidade. Uma história em que é narrada no tempo verbal do presente do indicativo, e, ao longo do tempo, essa narrativa será vista como uma história de vida passada no ano de 2020. Com a segunda análise, são apresentadas as narrativas de vida de várias pessoas espalhadas no mundo, nas quais expressam os seus sentimentos, as suas emoções e experiências vividas na pandemia da Covid-19 nos primeiros seis meses de 2020.

\section{REFERÊNCIAS}

ALMEIDA, C. A. de. Aspectos semânticos e pragmáticos da co-construção de identidades discursivas em narrativas de experiência de vida produzidas por participantes de emissões nocturnas de rádio" In: COSTA, A.; FALÉ, I.; BARBOSA, P. (Orgs.) Textos Selecionados XXVI Encontro Nacional da Associação Portuguesa de Linguística. Lisboa: APL, 2011, pp. 35-48.

BAMBERG, M.; MARCHMAN, V. A. What holds a narrative together? The linguistic encoding of episode boundaries. IPrA Papers in Pragmatics, v. 4, n. 1-2, p. 58-121, 1990. 
BASTOS, L. C.; BIAR, L. de. A. Análise de narrativa e práticas de entendimento da vida social. DELTA: Documentação e estudos em linguística teórica e aplicada, v. 31, n. 4, 2015.

Fundo das Nações Unidas para a Infância - UNICEF. (2020). Meu Herói és Tu. Como as crianças podem combater a COVID-19! 2020. Disponível em: https://www.unicef.org/brazil/comunicados-de-imprensa/livro-de-historias-infantislancado-para-ajudar-criancas-a-lidar-com-a-covid-19. Acesso em: 03 ago. 2020.

GOFFMAN, E. Interaction Ritual. New York: Doubleday Anchor, 1967.

GUMPERZ, J. Discourse strategies. Cambridge: Cambridge University Press, 1982.

GÜNTHNER, S. The construction of emotional involvement in everyday German narratives-interactive uses of 'dense constructions. Pragmatics, v. 21, n. 4, p. 573592, 2011.

LOPES, A. C. M. Tempo, aspecto e coesão discursiva. Actas do XI Encontro Nacional da Associação Portuguesa de Linguística, v. 3, p. 351-371, 1996.

MACAULAY, R. K. S. Polyphonic monologues: Quoted direct speech in oral narratives. IPRA Papers in Pragmatics, v. 1, n. 2, p. 1-34, 1987.

MEIRELLES, M. Pessoas que enfrentaram a Covid-19 contam como é a vida após a doença. CBN Globo Rádio. 2020. Disponível em: https://cbn.globoradio.globo.com/media/audio/306729/pessoas-que-enfrentaramcovid-19-contam-como-e-vid.htm. Acesso: 03 ago. 2020.

Enviado: Julho, 2020.

Aprovado: Agosto, 2020. 